\title{
A interação homem-máquina nas aeronaves tecnologicamente avançadas: a transformação de um paradigma
}

\section{Man-machine interaction in technologically advanced aircraft: transformation of a paradigm}

\author{
Mario Henrique Dorileo de Freitas Rondon¹, Clélia de Freitas Capanema², Rejane de Souza Fontes³ \\ Master's in Education from the Catholic University of Brasilia, and Specialist in Civil Aviation Regulation of the National Civil Aviation Agency (ANAC), \\ Brasilia, DF, Brazil. <mario.rondon@anac.gov.br> \\ 2 Prof. Dr. of the Postgraduate Program Strictu Sensu Masters in Education of the Catholic University of Brasilia, Brasilia, DF, Brazil. \\ Prof. Dr. in Education from the State University of Rio de Janeiro (UERJ) and Specialist in Civil Aviation Regulation of the National Civil Aviation Agency (ANAC), \\ Rio de Janeiro, RJ, Brazil. <rejane.fontes@anac.gov.br>.
}

\begin{abstract}
RESUMO
O artigo se propõe, com base em uma revisão bibliográfica, a apresentar uma discussão sobre a transformação dos processos de gerenciamento de aeronaves, caracterizados pela crescente automação da aviação, refletindo sobre a interação homem-máquina em aeronaves tecnologicamente avançadas (TAA). Baseado nos estudos desenvolvidos por Billings (1997), Hollnagel e Woods (2005), Henriqson, Carim e Gamermann (2011) e outros, o artigo procura definir o termo "automação" no campo da aviação como "uma nova forma de se fazer voar". Esta mudança, do "paradigma analógico" para um "paradigma digital”, modifica o modus operandi da aviação e requer novas formas de conhecimento. Neste sentido, é necessária uma nova interpretação da relação homem-máquina como sendo um sistema cognitivo e como tal, demandando novas dinâmicas de formação como aquelas baseadas em competências.
\end{abstract}

PALAVRAS-CHAVE: TAA; automação; interação homem-máquina; sistema cognitivo

\begin{abstract}
The article, based on a literature review, presents a discussion of the transformation of aircraft management processes, characterized by the increasing automation of aviation, and reflecting on the man-machine interaction in technologically advanced aircraft (TAA). Based on studies conducted by Billings (1997), Hollnagel and Woods (2005), Henriqson, Carim and Gamermann (2011), and others, the article seeks to define the term "automation" in the aviation field as "a new way of doing flying". This change, the "analog paradigm" to a "digital paradigm", alters the modus operandi of aviation and requires new forms of knowledge. In this sense, a new interpretation of the man-machine interface is required as a cognitive system and as such, demands new dynamic training, such as those based on competencies.
\end{abstract}

KEYWORDS: TAA; automation; man-machine interaction; cognitive system

Pontifical Catholic University of Rio Grande do Sul Porto Alegre, RS, Brazil

Editor

Thaís Russomano

Microgravity Centre PUCRS, Brazil

Executive Editor

Rafael Reimann Baptista

Faculdade de Educação Física e Ciências do Desporto, PUCRS, Brazil

e-ISSN: 2179-703X
Corresponding Author:

Rejane de Souza Fontes

rejane.fontes@anac.gov.br

Received: December 15, 2014

Accepted: December 26, 2014

(C) 2014 EDIPUCRS 


\section{Introdução}

Com as tecnologias de automação empregadas na aviação, conduzir uma aeronave vai além de uma atividade puramente mecânica, a pilotagem de aeronaves envolve a consciência e o gerenciamento de uma série de variáveis e fatores que interferem, direta ou indiretamente, na performance do piloto, na aeronave e na própria segurança de voo. $\mathrm{O}$ presente artigo se propõe a apresentar, através de uma revisão bibliográfica, alguns conceitos que estão surgindo no meio aeronáutico em função do crescente processo de automação das aeronaves e inauguram um novo paradigma na relação homem-máquina e no conceito de voar.

\section{Aeronaves tecnologicamente/ tecnicamente avancadas: o conceito de TAA (technically/ technologically advanced aircraft)}

A cabine de uma aeronave ou cockpit vem apresentando, ao longo dos últimos 30 anos, uma considerável elevação no uso de tecnologias responsáveis pelo controle e gerenciamento de um voo (NTSB, 2010).

Por volta dos anos 70 e 80, as aeronaves apresentavam alguns instrumentos, tais como o VOR, DME e o ADF, que eram responsáveis pelo direcionamento e orientação de um voo sem, contudo, retirar do piloto a necessidade de controle direto e constante, contendo pouco ou nenhum dispositivo eletrônico para o gerenciamento informatizado da operação aérea.

Atualmente, entretanto, o ato de voar é considerado por muitos especialistas mais um processo de gerenciamento de sistemas que um processo de destreza manual, em virtude da elevada presença de computadores e dispositivos eletrônicos em suas cabines de comando para um gerenciamento mais seguro, eficaz e econômico (AOPA, 2005).

Hollnagel e Woods (2005) afirmam que houve uma diminuição na utilização das habilidades motoras e um incremento das habilidades cognitivas na realização de operações aéreas, como pode ser identificado na Figura 1.

A Federal Aviation Administration - FAA (2003) define aeronaves com elevada presença de componentes digitais e computacionais em suas cabines de voo, como aeronaves tecnicamente ou tecnologicamente avançadas - TAA.

TAA, de acordo com FAA (2003), pode ser definida como sendo uma aeronave que possua, no mínimo, as seguintes características:

1. Certificado IFR ${ }^{1}$ com equipamento GPS de navegação com mapa móvel;

2. Um mostrador multifunção (MFD - multifunction displays), com mostrador meteorológico, de tráfego e gráfico de terreno; e

3. Um piloto automático integrado.

Em geral, as TAA's são aeronaves nas quais os pilotos interagem com um ou mais computadores para navegar e gerenciar os diversos sistemas do avião, bem como se comunicar com os outros elementos que compõem o sistema aéreo (FAA, 2003).

Esses instrumentos eletrônicos são apresentados em telas eletrônico-digitais que justificam, dessa forma, a denominação de cabines de vidro ou glasscockpit, como são comumente conhecidas as cabines das modernas aeronaves.

Figura 1. Atuação do equilíbrio no uso entre as funções cognitivas e manuais

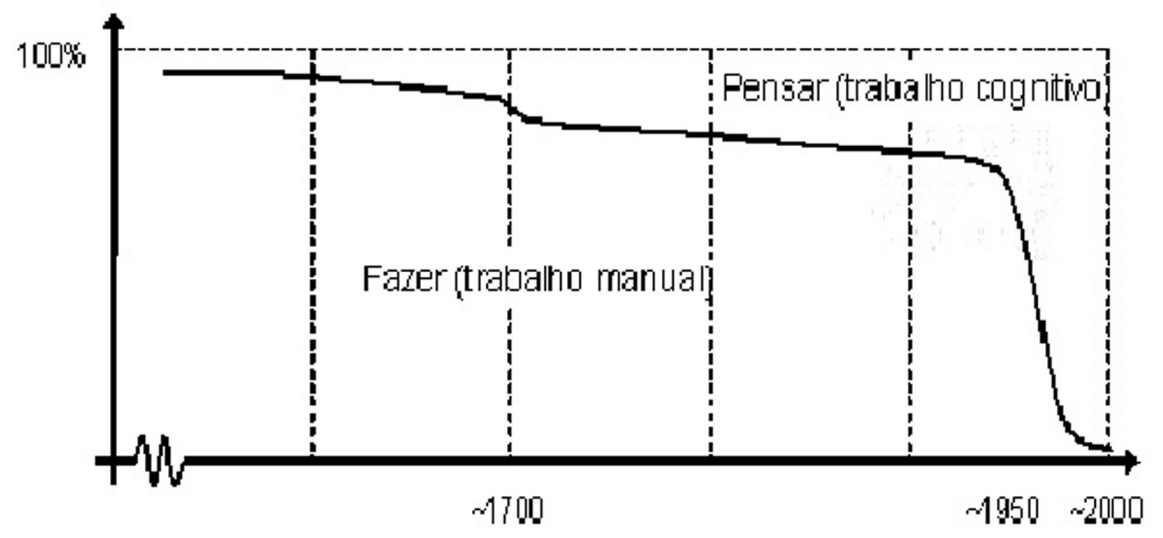

Fonte: Adaptado de Hollnagel e Woods (2005).

\footnotetext{
${ }^{1}$ IFR - Instrument flight rules (regras de voo por instrumento) - certificado IFR é uma habilitação conferida ao piloto que o habilita a realizar voos fora das condições de voo visual fazendo uso de dados provenientes dos instrumentos de voo a bordo da aeronave. No Brasil essa habilitação é prevista no Regulamento Brasileiro de Aviação Civil - RBAC 61 (Subparte L), cuja formação é orientada pelo Manual de Curso MMA 58-9, disponível no site da Agência Nacional de Aviação Civil < http://www2.anac.gov.br/habilitacao/manualCursos.asp > .
} 
De acordo com a AOPA Air Safety Foundation (2005), para poder se considerar uma aeronave glasscockpit deve-se incluir, ainda, além dos requisitos apresentados pela FAA, o mostrador primário de voo - PFD (primary flight display), o qual substitui os mostradores analógicos de instrumentos essenciais para a navegação, quais sejam: o horizonte artificial, o velocímetro, o altímetro, o indicador de atitude, o indicador de curva e derrapagem e o indicador de razão de subida e descida.

O conceito glasscockpit começou a ser testado pela National Aeronautics and Space Administration (NASA), em 1974, com as aeronaves modelo Boeing 737. Displays integrados e com elevada automação foram criados e introduzidos para possibilitar diminuição nos custos e um aumento nos índices de segurança das operações aéreas (NTSB, 2010).

Cabe salientar a importância nos aprendizados adquiridos em diversos acidentes e incidentes aeronáuticos ocorridos na aviação comercial, em especial, após a Segunda Guerra Mundial. Com a expectativa de crescimento da aviação, fazia-se necessária a melhoria nos equipamentos de controle das operações aéreas e do controle das aeronaves em voo.

É notória e irreversível a introdução de aeronaves tecnologicamente avançadas no setor de transporte aéreo, bem como em todos os setores da aviação, tais como as aeronaves - Airbus 320/330/340/380 e o Boeing 747/777 - equipadas com um avançado sistema de automação, o qual tem incorporado em sua lógica de controle cálculos que previnam, dentre outros pontos, a aeronave de exceder seus limites operacionais, fazendo com que os aviões permaneçam, durante a operação, dentro de seu envelope estrutural ${ }^{2}$ e dentro de limites mais econômicos de voo (ICAO, 1998).

O Quadro 1 apresenta um mapeamento da evolução tecnológica embarcada em aeronaves no último século.
O conceito de PBN, difundido a partir da terceira edição do DOC 9613 (Performance Based Navigation Manual - International Civil Aviation Organization ICAO), resulta do esforço da ICAO em harmonizar os métodos de navegação aérea.

A introdução e desenvolvimento da navegação conhecida como PBN (Performance-Based Navegation), ou seja, navegação baseada em desempenho ainda se encontra em processo de implantação no Brasil. De acordo com a IS 21-013 (revisão A) da ANAC,

O conceito de PBN estabelece que os requisitos do sistema RNAV da aeronave sejam definidos em termos de: precisão, integridade, disponibilidade, continuidade e funcionalidade. Ele representa a mudança da navegação baseada em sensores para a navegação baseada em desempenho. (Brasil, 2012, p. 4)

Ou seja, é um Sistema de Navegação Multissensor (Brasil, 2012) que auxilia o voo provendo orientação espacial à aeronave. A IS 21-003 (Revisão A), p. 2, ainda afirma que

este tipo de sistema de navegação calcula e exibe uma posição oriunda de uma única ou várias fontes de navegação como, por exemplo, GNSS ou GNSS-WAAS (Wide Area Augmentation System), Loran-C (Long Range Navigation), VOR/DME (VHF Omnidirectional Range/Distance Measuring Equipment), DME/DME, ou sistemas inerciais INS (Inertial Navigation System)/IRS (Inertial Reference System)/IRU (Inercial Reference Unit).

Um dos riscos que atualmente existem sobre o uso do GNSS ${ }^{3}$ para operações aéreas é a interrupção do sinal que pode ocorrer a qualquer momento em qualquer região do planeta, devido à interferência intencional dos Estados Unidos, detentor da tecnologia GPS, que é o único totalmente operacional. Esta interrupção pode

Quadro 1. Resumo da evolução tecnológica das aeronaves

\begin{tabular}{|l|l|c|}
\hline \multicolumn{1}{|c|}{ Período } & \multicolumn{1}{|c|}{ Inovações Tecnológicas } & Ex. De Aeronaves \\
\hline Década de 30 & Desenvolvimento do giroscópio e sua utilização nos instrumentos de bordo. & Junkers F-13 \\
\hline Década de 50 e 60 & Desenvolvimento de sistemas aeronáuticos relacionados com a operação das aeronaves & Douglas DC-3 \\
\hline Década de 60 e 70 & $\begin{array}{l}\text { Desenvolvimento e consolidação de grandes aviões de transporte propulsados com } \\
\text { motores a reação. }\end{array}$ & Boeing 707 \\
\hline Década de 70 e 80 & $\begin{array}{l}\text { Desenvolvimento e consolidação de sistemas autônomos de navegação e redução de } \\
\text { tripulantes técnicos a bordo através da automação de funções. }\end{array}$ & Boeing 767 \\
\hline Década de 80 e 90 & Desenvolvimento e consolidação de sistemas de navegação por satélites. & Airbus 330 \\
\hline $\begin{array}{l}\text { Década de } 90 \text { aos } \\
\text { dias atuais }\end{array}$ & $\begin{array}{l}\text { Desenvolvimento e consolidação de sistemas de gerenciamento em cabines de alta } \\
\text { tecnologia digital. }\end{array}$ & Boeing 787 \\
\hline
\end{tabular}

Fonte: Ribeiro (2008).

\footnotetext{
${ }^{2}$ Envelope estrutural - limitações estruturais que devem ser consideradas durante a realização de uma operação aérea respeitando os limites propostos durante o projeto estrutural de uma aeronave.
}

3 Sistema de navegação por satélites baseado no GNSS - Global
Navigation Satellite Systems que auxilia o voo provendo orientação
espacial à aeronave. É um sistema global de determinação de 
ocorrer, por exemplo, devido a testes militares. Como consequência, a aeronave pode perder a indicação do seu posicionamento, mesmo que existam acordos internacionais que previnam esse tipo de interrupção.

Os sistemas de satélites europeu e russo ainda não cobrem toda a superfície do planeta para serem utilizados como alternativa ao GPS.

Os sistemas de navegação de área permitem o voo em qualquer trajetória desde que a aeronave se encontre dentro da cobertura dos auxílios à navegação (por satélite ou em terra) ou dentro da capacidade dos equipamentos de posicionamento embarcados, ou uma combinação de ambos. (Brasil, 2013, p. 2-3)

Em suma, entre as conquistas proporcionadas com a introdução de novas tecnologias, dentre elas a possibilidade da realização do voo com base na performance (PBN), estão: o voo ponto a ponto, otimizando o tempo e ampliando o aproveitamento do espaço aéreo, com rotas menores, menos gasto de combustível, maior flexibilidade de voo, menos emissão de poluentes, pousos de precisão por satélites, aproximações com descida contínua e trajetórias de voo muito mais precisas.

Para muitos pilotos, o sistema GNSS pode representar uma experiência nova com sistemas tecnológicos embarcados que requerem programação ao invés da simples seleção de frequências. Tal fato associado à crescente variedade de dispositivos eletrônico-digitais aponta para a necessidade de se capacitar a tripulação na operação dos sistemas GNSS, como exemplo. Dessa forma, os operadores aéreos devem assegurar que seus pilotos estejam devidamente capacitados para realizarem as mais diferentes operações, assegurando um grau mais elevado de conhecimento (trabalho cognitivo) do que apenas a habilidade psicomotora (trabalho manual).

\section{Automação: definição, níveis e necessidades}

De acordo com Kaber, Riley e Tan (2002), um dos maiores desafios para os pilotos na operação das avançadas aeronaves glasscockpit é a efetiva compreensão e a interação bem sucedida como todo o sistema de automação.

posição, direcionamento e tempo (sincronismo), que inclui uma ou mais constelações de satélites, receptores de bordo e monitores de integridade, bem como os sistemas de aprimoramento de sinal necessários à adequação aos requisitos de desempenho de navegação para cada tipo de operação. Alguns dos sistemas GNSS
Billings (1997) relata que 65\% a $80 \%$ dos acidentes ou incidentes no transporte aéreo são atribuídos em parte, ou totalmente, ao erro humano. E a automação, de acordo com o autor, ingressou na aviação com o intuito, dentre outros pontos, de diminuir a frequência de erros humanos nas operações aéreas, automatizando as tarefas dos pilotos. Mas, qual seria uma definição de "automação" adequada para o vocábulo no campo da aviação? De acordo com Billings (1997, p. 6), automação refere-se ao "sistema ou método que em quase na totalidade seus processos de produção são executados automaticamente ou controlados por sistemas autônomos".

A primeira revista científica a utilizar o termo automação foi a Scientific American Article, em 1952. Atualmente, o termo está amplamente difundido em todos os campos do conhecimento, e em um sentido contemporâneo, de forma bem completa, de acordo com Sheridan e Parasuraman (2005), o termo automação refere-se:

a) à mecanização e integração dos dados captados referentes às variáveis do ambiente envolvido, por meio de sensores artificiais;

b) ao processamento de dados e ao "processo de decisão" realizado por computadores;

c) à ação mecânica por motores ou equipamentos; e

d) à "ação informacional" quando da apresentação, para o operador, por meio das telas digitais, das diversas informações e dos dados referentes a determinado momento de um voo.

Para Kaber, Riley e Tan (2002), uma aeronave moderna será considerada "glass"cockpit (cabine de vidro) em virtude das telas nas quais se apresentam as informações de navegação, da utilização a bordo de um sistema de gerenciamento de voo, denominado FMS (Flight Management System), bem como da disposição de uma unidade de controle multifuncional - MCDU (Multifunction computer display unit).

Bhana (2010) apresenta a automação como algo que se refere ao controle de um processo ou mesmo de um sistema por meio de uma máquina ou equipamento eletrônico.

A utilização de artefatos ${ }^{4}$ eletrônicos nas mais diversas atividades, neste caso na atividade aérea, define o que Hollnagel e Woods (2005) denominaram de sistemas cognitivos de engenharia, caracterizados pelo uso crescente de complexos sistemas sociotecnológicos para a execução das mais diversas tarefas.

conhecidos são o norte-americano GPS, o europeu Galileu, o russo GLONASS.

${ }^{4}$ Denominação utilizada por Hollnagel e Woods (2005) para todo e qualquer equipamento que amplia ou amplifica a potencialidade do homem na execução de determinada tarefa ou atividade. 
Para os autores, o uso da automação vem se fazendo presente desde a década de 30. Entretanto, é a partir da década de 70, com o surgimento dos computadores e suas facilidades, que houve uma revolução no que diz respeito à presença da tecnologia para o uso na aviação e, consequentemente, a transformação na interação da aeronave com o homem, criando assim novas demandas cognitivas para a realização da atividade (Hollnagel e Woods, 2005).

Como já comentado, a cabine de voo de uma aeronave glasscockpit ou TAA caracteriza-se por possuir inúmeros displays de instrumentos eletrônicos com telas em LCD (cristal líquido) ou CRT (tubos de raios catódicos). Estas diferenças são marcantes em relação a um painel de uma aeronave tradicional que depende de instrumentos mecânicos para a exibição das informações referentes ao voo.

Mais que caracterizar um tipo de aeronave, o termo 'glasscockpit' define uma nova forma de se fazer voar, dando ênfase ao gerenciamento de diversos sistemas que apresentam o resultado dos dados obtidos pelos computadores dos aviões e são repassados para análise dos pilotos (Billings, 1997).

Essa característica atual das operações aéreas, a mudança de um 'paradigma analógico' para um 'paradigma digital', modifica o modus operandi da aviação. Pilotos precisam agora aprender a lidar com as técnicas de gerenciamento dos sistemas automatizados e obter informações precisas do enorme volume de dados obtidos pelos computadores das aeronaves em tempo real (Bhana, 2010).

Cabe ressaltar que para diferentes tipos de sistema de automação existe um nível diferenciado e característico de ingerência em seu uso. Alguns sistemas requerem a presença e intervenção constante de seus operadores enquanto outros já são absolutamente independentes (Bhana, 2010).

\subsection{Níveis de automação}

Billings (1997) afirma que a interação do piloto com a cabine automatizada é fundamental para a execução das tarefas de pilotagem, tais como controle de voo, navegação e comunicação.

Sarter (1991 apud Kaber, Riley e Tan, 2002), em um estudo com pilotos, identificou na interação desses com o Sistema de Gerenciamento de Voo - FMS, que $67 \%$ dos pilotos continuavam surpresos com sua operacionalidade e pouco mais de $45 \%$ não entendiam completamente a operação e a funcionalidade do FMS.

A partir da década de 1960 , com a instalação de sistemas automatizados, iniciou-se o afastamento do piloto do comando manual das aeronaves (Monteiro, 2007), como apresenta a Figura 2.

Figura 2. Evolução da automação nas aeronaves de transporte

\section{EVOLUÇÃO DO USO DA AUTOMAÇÃO NAS AERONAVES DE TRANSPORTE}

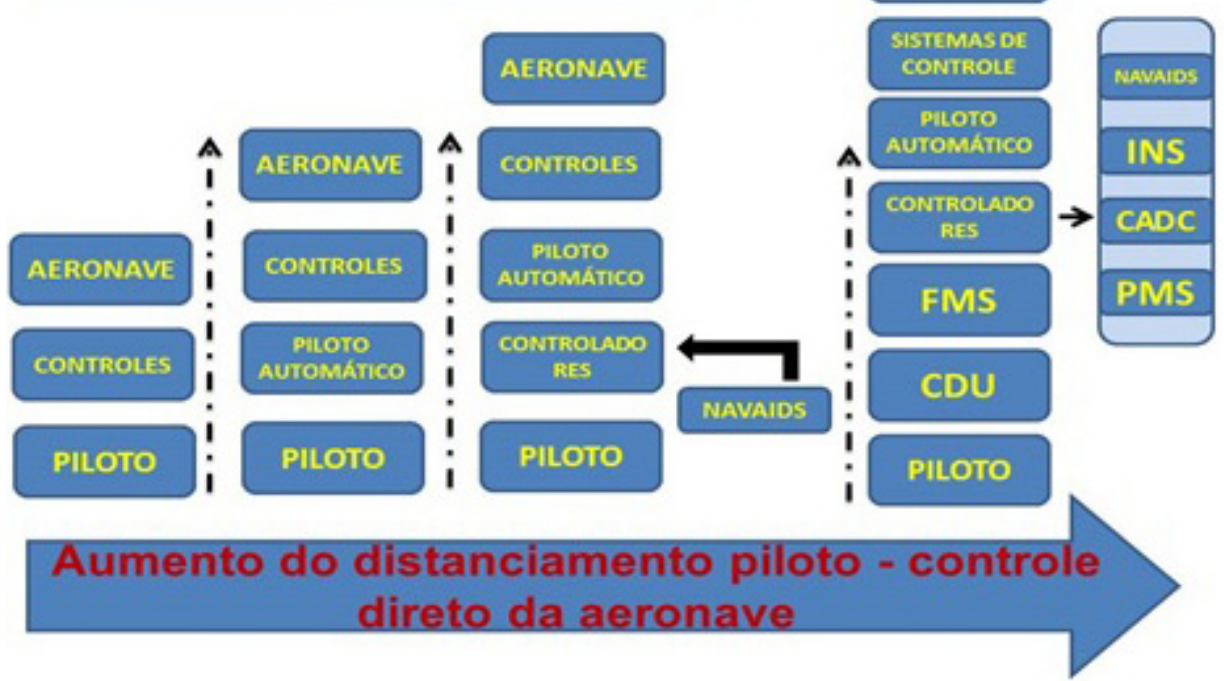

NAVAIDS - auxílios de navegação; CADC - Center Air Data Computer (computador central de geração de dados); INS - Inertial Navigation System. Um sistema baseado em giroscópio que sente a aceleração e a desaceleração, analisa e computa a posição da aeronave em latitude e longitude com muita precisão. Usado normalmente para a aviação de longo raio, aeronaves militares e sofisticados jatos. Também conhecido como IRS - Inertial Reference System; PMS - Performance Management System (sistema de gerenciamento de desempenho).

Fonte: Adaptado de ICAO (1998) 
Pode-se observar, na Figura 2, que os pilotos possuíam maior contato com os sistemas e controles das aeronaves, e agora possuem responsabilidade no gerenciamento dos complexos sistemas tecnológicos que controlam a operação das aeronaves por meio das telas de interface (ICAO, 1998).

Como já comentado, a automação tem se justificado em virtude, muito especial, da manutenção benéfica entre a segurança nas operações e a economia para o setor (Henriqson, Carim e Gamermann, 2011).

No tocante à segurança, aponta-se para a contribuição quanto à redução nas possíveis falhas humanas, à redução da carga de trabalho, em determinados momentos, à maior precisão nas operações, promovendo, por exemplo, uma separação mais efetiva entre as aeronaves no espaço aéreo.

Para a economia aponta-se a redução dos custos nas operações e do desgaste prematuro em componentes da aeronave (Henriqson, Carim e Gamermann, 2011).

O distanciamento apresentado entre homens e máquinas é também analisado por Hollnagel e Woods (2005), como apresentado na Figura 3 abaixo.

$\mathrm{Na}$ Figura 3, pode-se identificar a existência de quatro estágios ou gerações relativos à utilização da tecnologia. No primeiro, chamado de "controle manual", homens atuam de forma direta com o artefato, ou seja, o piloto atuava diretamente nos controles das aeronaves, e mesmo que houvesse a presença de uma tecnologia simples, as informações eram pelo piloto, identificadas, analisadas, trabalhadas e direcionavam por meios próprios as ações a serem efetivadas (Hollnagel e Woods, 2005).

No segundo estágio, denominado "controle supervisionado", verifica-se certa diminuição na interação do homem com o processo direto, proporcionado pela utilização de tecnologia em algumas áreas. $\mathrm{O}$ piloto, por exemplo, passa a atuar nas aeronaves por meio do piloto automático, que então atuava na aeronave (Figura 3).

Hollnagel e Woods (2005) afirmam que, a partir desse estágio, a relação do homem com a máquina começa a sofrer uma alteração natural, o que justificaria uma mudança de paradigma na forma como se identifica a automação, suas peculiaridades e a interação daquela com o homem.

Para os autores, neste estágio, o relacionamento passa a ter uma conotação mais cognitiva, uma vez que o artefato, neste caso o piloto automático, passa a ter um controle diretivo sobre a aeronave.

No próximo estágio - o terceiro - como pode ser identificado na Figura 3 o piloto passou a atuar em controladores, que por sua vez, agiam no piloto automático e então atuavam nos controles da aeronave.

Figura 3. Estágios de dependência homem-máquina
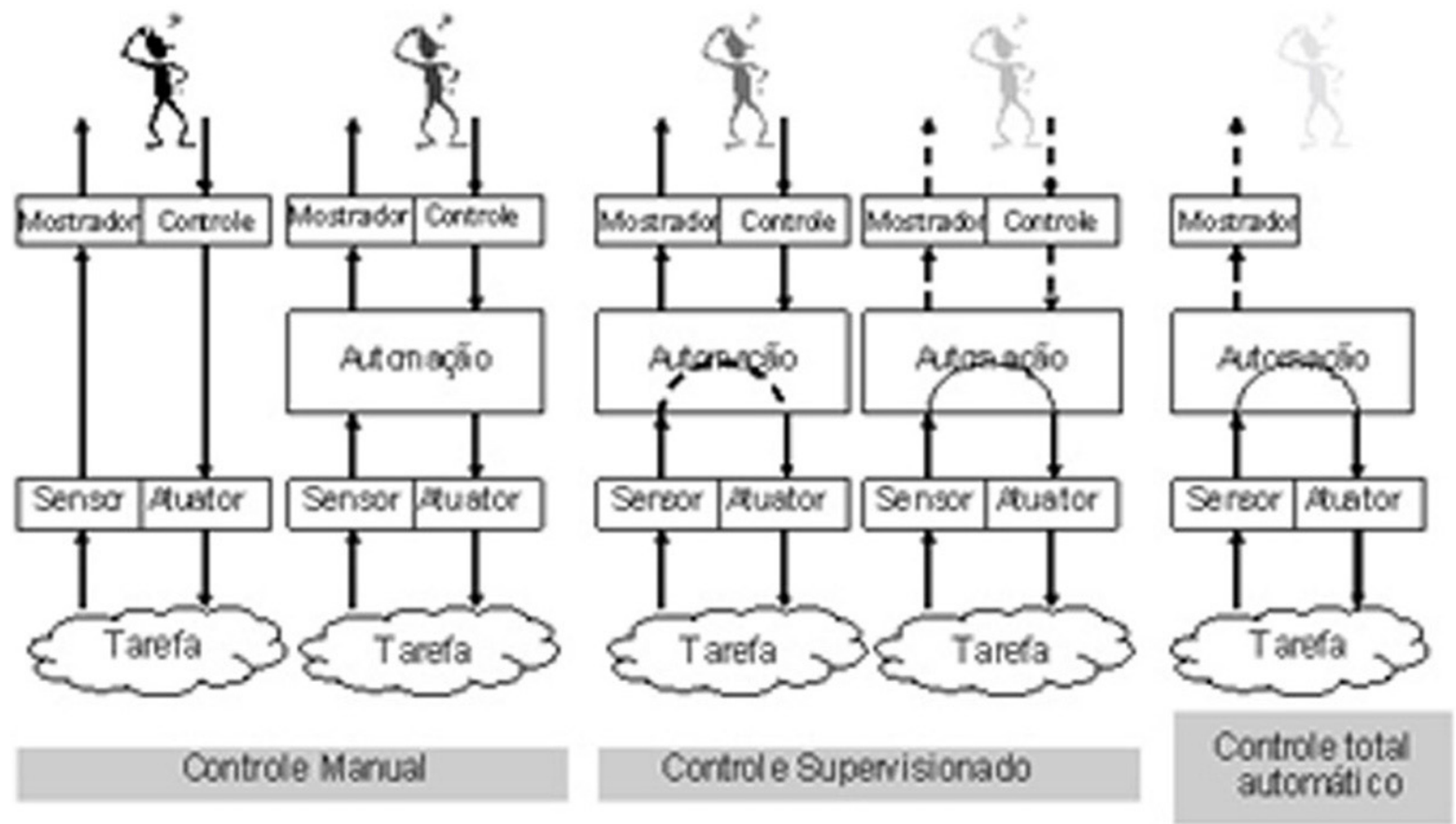

Fonte: Adaptado de Hollnagel e Woods (2005) 
Por fim, no quarto estágio, percebe-se a presença da automação de forma mais ou menos completa no processo, e o operador tendo sua possibilidade de intervenção bastante reduzida e, em alguns casos, totalmente reduzida.

Como aponta Hollnagel e Woods (2005), uma das consequências diretas da evolução no uso da automação nos diversos setores é a mudança na forma como se lida com essas tecnologias.

Endsley e Kaber (1999 apud Sheridan e Parasuraman, 2005) demonstraram que os níveis de automação afetam diretamente o desempenho, a consciência situacional e a carga de trabalho na dinâmica de controle de uma tarefa.

Sheridan e Parasuraman (2005) e Hollnagel e Woods (2005) afirmam que já com o advento do segundo estágio, o controle supervisionado, tem-se uma questão central a ser bem trabalhada no processo de automação de qualquer setor, a relação ou relacionamento entre homem e a máquina, que de forma rudimentar podese afirmar que a máquina, aqui, pode ser considerada como tendo certa 'inteligência'.

A relação com uma máquina provida de certa 'inteligência' promove uma diferença radical quanto à maneira com que o homem interage com aquele artefato.

Para Sheridan e Parasuraman (2005), sistemas tecnológicos com diferentes níveis de participação da automação tem sua utilização orientada de acordo com os diversos estágios de uma atividade qualquer, de forma a atender diferenças em sua filosofia e/ou necessidade de uso.

Os autores identificaram oito níveis relacionados ao uso da automação:

1. O computador não oferece assistência, o operador deve fazer tudo;

2. O computador sugere formas alternativas para se executar uma tarefa;

3. O computador seleciona uma forma para se executar determinada tarefa e

4. Executa o que foi sugerido se o operador autorizar; ou

5. Permite que o operador tenha um tempo restrito para vetar determinada tarefa antes que execute automaticamente; ou

6. Executa a tarefa proposta automaticamente, e então necessariamente informa ao operador; ou

7. Executa automaticamente a tarefa, então informa ao operador se o sistema for questionado.

8. O computador seleciona o método, executa a tarefa e ignora o operador.

$\mathrm{Na}$ aviação, a automação é desenhada de forma a responder em um espectro mediano, ou seja, 'executa' a ação automaticamente, e então, necessariamente, informa ao operador, o piloto (Bhana, 2010).

A automação na aviação tem sofrido incrementos quanto à sofisticação e integração nos diversos sistemas. A questão central na discussão do uso da automação é a interação do homem/operador/piloto com a máquina/ aeronave e sistemas automatizados (Bhana, 2010).

E nesse ponto, o paradigma digital requer do piloto habilidades diferentes das que eram exigidas em um ambiente caracterizado pelo paradigma analógico (Bhana, 2010; Henriqson, Carim e Gamermann, 2011).

Hoje, pilotos programam os computadores de suas aeronaves para gerenciarem os sistemas de voo utilizando um teclado digital, para que o 'piloto automático', por meio de cálculos realizados por seus sistemas de gerenciamento de voo, aponte os parâmetros necessários em sua decolagem, e então os levem para uma nova altitude ou nível de voo, em certa proa ou certo rumo; voando por sobre determinados pontos de controles previamente programados e inseridos em seus computadores, e daí poderem realizar, por exemplo, um padrão de descida a fim de pousarem em outro aeroporto (Sheridan e Parasuraman, 2005).

Todos esses procedimentos são trabalhados com parâmetros que garantam a segurança na operação aérea. Do ponto de vista da aeronave/piloto, estes parâmetros primam pela permanência de uma atividade dentro de envelopes estruturais de desempenho seguro; do ponto de vista do tráfego aéreo, definem o distanciamento entre aeronaves e o sequenciamento aéreo seguros; e que garantam economia no setor, tanto quanto a melhor definição de rotas aéreas como no menor consumo de combustível.

\section{Interação homem-máquina: mudando o paradigma}

Para Hollnagel e Woods (2005), mais importante que um processo de desenvolvimento e aumento na complexidade dos sistemas tecnológicos para atender as expectativas de seus operadores, é a mudança no paradigma utilizado para se entender esse processo de interação entre o homem e a máquina.

Hollnagel e Woods (2005) apontam que, normalmente, as interpretações das mensagens são reconhecidas de acordo com um padrão apresentado pela proposta do modelo Shannon-Weaver, na qual o homem responderia a estímulos, basicamente de forma linear e por meio de inputs (entradas) e outputs (saídas) de informações na interação com o sistema envolvido, em um padrão conhecido como S-O-R (Stimulus, Organism and Response) ou (estímulo, organismo e resposta). 
Portanto, um piloto, voando sua aeronave, sentiria, por exemplo, uma modificação no vento relativo ${ }^{5}$ da navegação; tal estímulo proveniente da interação direta piloto-avião, faria com que o piloto, em um processo interno, dinâmico e particular, compreendesse a necessidade de se realizar uma correção de proa a fim de manter-se corretamente em um rumo, o que resultaria na reposta do piloto, atuando nos controles da aeronave.

Para Hollnagel e Woods (2005), o paradigma típico do processo de informação, dava-se basicamente dentro da mente do homem, sem considerar, entretanto, outros fatores e variáveis envolvidas, um paradigma que Henriqson, Carim e Gamermann (2011) denominaram de analógico.

Hollnagel e Woods (2005) propõem, portanto, um novo paradigma para a percepção da interação do homem-máquina, o que para eles seria uma forma mais ativa e integrada do conceito de "diálogo" entre ambos. Tal paradigma deixaria de ser entendido como um simples processo interno de informação e passaria a ser percebido como um processo de 'cognição mental'.

Essa mudança na percepção do processo busca mais que uma modificação na interpretação do envolvimento homem-máquina, mas também possibilitar a compreensão de que as respostas do homem a um determinado evento devam ser analisadas em determinado contexto, com ferramentas cognitivas e adequada formação dos operadores.

Mais que um processo de interação, para Hollnagel e Woods (2005), a relação homem-máquina deve ser percebida como uma 'ação coordenada' entre homem e tecnologia, sendo compreendida ação coordenada como o estado de 'estar em ação', de estar em constante supervisão, de forma a se manter ótimos níveis de consciência situacional.

Ao se aceitar um modelo no qual as ações do homem, para se alcançar determinado fim, são percebidas como cíclicas e não lineares, e, portanto, devam ser compreendidas como ações coordenadas homem-máquina, algumas consequências diretas se assumem de acordo com Hollnagel e Woods (2005), dentre elas:

1. as ações são percebidas em conjunto e não independentemente. $O$ paradigma cíclico enfatiza que ações são tidas por um processo de experiência e que antecipem atitudes futuras.

\footnotetext{
5 Tem o mesmo valor que a velocidade aerodinâmica, mas não representa o deslocamento. Representa o escoamento de ar em relação à asa. $\mathrm{O}$ sentido do vento relativo é oposto ao da velocidade aerodinâmica. É o vento aparente que sopra sobre um corpo em movimento na atmosfera, geralmente no sentido contrário ao objeto em movimento.
}

2. foca-se a antecipação mais que a resposta. Como pode ser percebido na Figura 4, o modelo cíclico para entendimento do processo de ação coordenada entre homem e tecnologia não possui início ou fim, o que sugere que qualquer esforço para um bom desempenho se faça por meio da interpretação de fatos passados, e da expectativa do que pode vir a ocorrer em diferentes momentos no futuro.

Figura 4. Elementos que integram um sistema cognitivo de engenharia

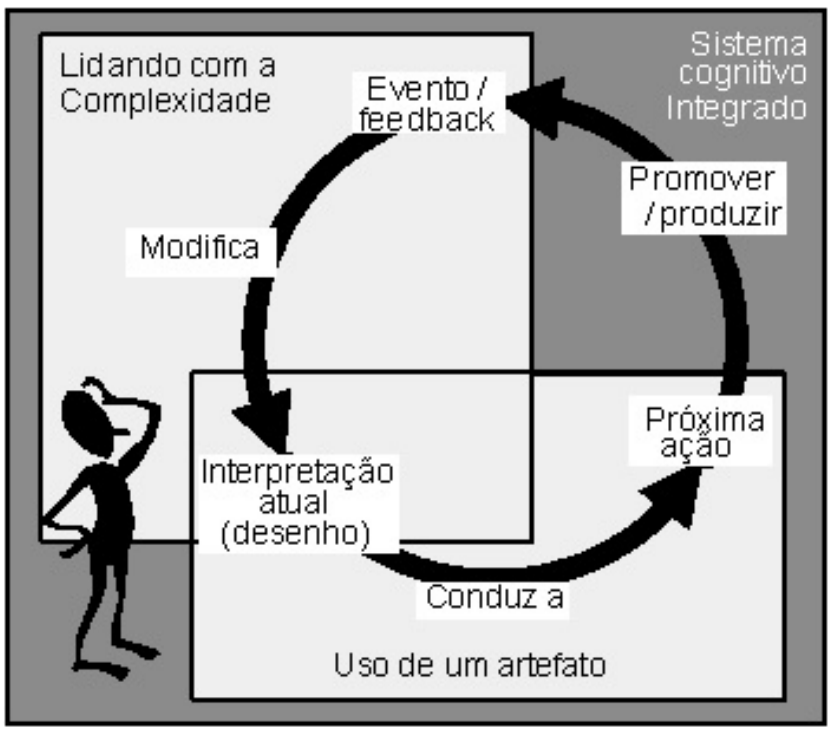

Fonte: Adaptado de Hollnagel e Woods (2005).

O modelo cíclico de compreensão da interação entre homem e tecnologia, portanto, combina retroalimentação de fatos passados e previsões com possíveis eventos.

3. usuários de sistemas tecnológicos são percebidos como parte de um conjunto maior. O modelo cíclico foca na ação coordenada, em como usuários e ambiente estão dinamicamente envolvidos, e como as ações e os eventos estão mutuamente dependentes.

4. é direta a influência do contexto e das situações. Neste modelo, entende-se que o contexto pode afetar a forma de trabalho e interação homem-tecnologia, especificamente como os eventos são avaliados e de que forma as ações são selecionadas.

5. modelos são mais funcionais que estruturais. A ênfase do modelo cíclico é no desempenho, mais que no processo interno.

Para Hollnagel e Woods (2005), é importante a percepção cognitiva na interação homem-máquina como se homem e máquina fosse um único sistema de forma a se alcançar o resultado esperado.

Cada um com suas peculiaridades e limitações, a relação homem-máquina pode ser entendida como 
sendo a operação de um Sistema Cognitivo Integrado Joint Cognitive System (JCS), no qual duas 'inteligências' se interagem para alcançar determinado fim (Hollnagel e Woods, 2005).

Afinal, para Hollnagel e Woods (2005), um 'Sistema Cognitivo' diz respeito a um sistema que consegue modificar seu comportamento com base em 'experiência adquirida' e, com isso, manter o controle das diversas situações, sejam normais ou anormais, esperadas ou não, atingindo, ao término de um processo ou uma fase determinado fim.

Para Hollnagel e Woods (2005), um Sistema Cognitivo Integrado apresenta uma ou mais das seguintes características:

1. Um funcionamento não trivial, no qual geralmente exige mais que uma simples ação para atingir um resultado ou obter uma resposta do artefato. Para artefatos mais complexos, para tecnologias mais complexas, uso adequado vai requerer um melhor planejamento ou 'agendamento' - antecipação e conhecimento do funcionamento do artefato.

2. O funcionamento do artefato é, até certo ponto, imprevisível ou ambíguo, para qualquer uma das razões acima mencionadas.

3. O uso do artefato implica em um processo dinâmico, no qual o ritmo ou desenvolvimento dos eventos não é orientado para o utilizador/ operador. Como consequência tem-se que tempo é um recurso limitado.

Entende-se artefato como sendo qualquer tecnologia que amplifique a capacidade de o homem executar uma atividade. Especificamente para este artigo, trabalhamos com a ideia do uso de complexos sistemas sociotécnicos na condução das modernas aeronaves.

Por sistemas cognitivos pode-se entender, portanto, como sendo um sistema direcionado e focado em resultados, com base em símbolos manipuláveis, adaptável e capaz de analisar um mesmo problema de diversas formas e operar com base em seus dados e nas informações obtidas do ambiente, além de ser capaz de planejar e modificar determinadas ações com base em seu conhecimento prévio, obtendo feedbacks de informações e experiências passadas e prevendo alternativas para futuros eventos.

Neste sentido, o desenvolvimento dos sistemas cognitivos exige, por sua vez, também uma formação do piloto diferenciada daquela até então empregada para o manuseio dos equipamentos da aeronave dentro de um "paradigma analógico". A formação por competências representa uma destas possibilidades, sendo entendida como um conjunto de recursos (background) formado por conhecimentos, atitudes e habilidades, por meio do qual o desempenho de um indivíduo seria aferido com a demonstração (materialização) de um conhecimento na prática.

O trinômio conhecimentos/habilidades/atitudes (CHA) embasa o conceito de competência. Resumidamente, entende-se por conhecimento os conceitos, ideias e teorias sobre determinado assunto e está relacionado à capacidade de pensar, estabelecer conexões entre ideias e diagnosticar soluções para os problemas. Já o conceito de habilidade deve ser compreendido como o fazer com o emprego do conhecimento na execução técnica de uma atividade. Por fim, entende-se por atitude, dentro deste trinômio, ao relacionamento interpessoal, envolvendo a capacidade de se comunicar, cumprir regras, coordenar, liderar e resolver conflitos.

Em uma perspectiva mais ampla, compreende-se competências como um conjunto holístico e integrado, combinando-se atributos e contexto, ou seja, uma combinação complexa de atributos necessários para o desempenho (geralmente profissional) em situações específicas (Araújo, 2007).

Assim, dentro de um "paradigma digital" a capacidade de tomar decisões e a experiência estão estreitamente relacionadas na operacionalização de uma competência. Uma competência só pode ser constituída na prática com base nos conhecimentos, habilidades e atitudes adquiridas pelo sujeito. É preciso que o sujeito aprenda para que serve o conhecimento, quando e como aplicá-lo no gerenciamento das diferentes variáveis que agora estão envolvidas na condução da aeronave.

É imprescindível, pois, uma nova interpretação na relação homem-máquina, para que se possam obter melhores resultados nas diversas áreas que fazem uso da automação para sua execução. $\mathrm{Na}$ era digital, entender o binômio homem-máquina como sendo um sistema cognitivo, possibilitaria ao operador dos diversos equipamentos tecnológicos maior controle sobre os resultados esperados e melhor efetividade nas situações não usuais ou anormais.

\section{Considerações finais}

Em virtude desta nova forma de se fazer voar, os profissionais do ar, pilotos, reguladores, e todos os envolvidos no sistema aeronáutico, precisam identificar as diferenças ressaltadas pelo uso de artefatos que visam dar maior qualidade na realização das operações aéreas.

Pilotos devem aprender a lidar com as técnicas de gerenciamento dos sistemas automatizados de forma a poderem responder de forma satisfatória à obtenção de 
informações precisas do enorme volume de dados obtidos pelos computadores das modernas aeronaves em tempo real. A automação pode ser um elemento fortalecedor da Segurança Operacional, bem como um desagregador do sistema de segurança.

O lado da balança a ser orientado, se um fortalecedor ou um desagregador, irá depender da percepção de novas demandas quanto à formação desses profissionais para o setor.

Com o tempo, o distanciamento do piloto no controle direto da aeronave vem apontando para a necessidade de se rever o processo de formação desses profissionais, que atualmente possuem responsabilidade no gerenciamento dos complexos sistemas tecnológicos que controlam a operação das aeronaves. Esse controle, por meio de telas de interface, displays eletrônicos, contudo, não minimizam a importância de se qualificar tais profissionais tanto com relação às habilidades psicomotoras como cognitivas. Pelo contrário. Observa-se que uma boa qualificação da tripulação tem sido apontada como fator essencial na diminuição dos erros que levam a acidentes/incidentes aeronáuticos.

É certo, com vistas as mais diversas pesquisas, que a relação com uma máquina provida de certa 'inteligência' promove uma diferença radical na maneira com que o homem interage com aquele artefato. Por isso, a relevância em uma releitura na discussão do uso da automação pelos pilotos, em particular, bem como da interação de homem/operador/piloto com a máquina/artefato/aeronave e sistemas automatizados.

Essa discussão aponta a urgência de se rever o processo de formação dos pilotos nas escolas de aviação no país. O paradigma digital requer habilidades diferentes das que eram exigidas em um ambiente caracterizado pelo paradigma analógico, sem, contudo, desprezar a importância de se aprimorar tanto as habilidades cognitivas quanto as psicomotoras.

Como defendido por teóricos como Hollnagel e Woods (2005), mais importante que um processo de desenvolvimento e aumento na complexidade dos sistemas tecnológicos para atender as expectativas de seus operadores, é a mudança no paradigma utilizado para se entender esse processo de interação entre o homem e a máquina.

Essa mudança na percepção do processo de interação homem-máquina busca mais que uma modificação na interpretação do envolvimento desse binômio, possibilita a compreensão de que as respostas do homem a um determinado evento devam ser analisadas em determinado contexto, com ferramentas cognitivas e adequada formação desses pilotos.

O que se busca são conhecimentos, habilidades e atitudes adequados para uma ação e/ou reação que vise à manutenção em níveis ótimos de segurança operacional quando do uso por parte desses profissionais da automação, cada vez mais presente, nas mais simples atividades do setor.

Seja em busca de segurança, seja em busca de economia, a automação é uma realidade que deve ser melhor analisada e introduzida de maneira consciente, respeitando-se os limites humanos.

Diferentemente das máquinas, o homem apresenta limitações que de forma alguma reduzem sua importância no ciclo de determinada atividade. Ao contrário, aperfeiçoar todos os elementos fortalecedores do FATOR HUMANO, é um dos pontos mais relevantes de qualquer política voltada à manutenção da segurança operacional.

Deve-se compreender que o desenvolvimento e o uso dos sistemas cognitivos complexos exigem que a formação dos pilotos acompanhe tal demanda. Sem nenhum intuito de diminuir a importância do paradigma analógico e sua necessidade de aprimoramento psicomotor, o emprego de equipamentos que fazem uso de sistemas balizados por um paradigma digital, requer, da mesma forma, um acompanhamento para a formação das competências essenciais a esse novo momento da aviação.

Idealmente, perceber a integração de ambos os paradigmas (analógico e digital) e suas nuances no processo de formação e qualificação de competências a esses profissionais afetará de maneira consistente o conjunto de recursos (conhecimentos, habilidades e atitudes) que compõem o arcabouço de competências dos pilotos para poderem lidar de maneira mais propícia com as mais variadas demandas do meio aeronáutico.

\section{Referências}

Aircraft Owners and Pilots Association - AOPA. Air Safety Foundation Report, Technically advanced aircraft report - safety and training. Safety Center, 2005. Disponível em: < http://www. aopa.org/asf/publications/taa_1_6.pdf>. Acesso em: 10 set. 2011.

Araújo D. Noção de Competência e Organização Curricular. Revista Baiana de Saúde Pública (Salvador) jun. 2007; 31 (sup. 01):31-43.

Billings CE. Aviation automation: the search for a humancentered approach. Mahwah, NJ: The Ohio State University/ Lawrence Erlbaum Associates Publishers; 1997.

Bhana $\mathrm{H}$. Trust but verify. The journal of flight safety foundation. Jun 2010; 5. Disponível em: <http://flightsafety.org/asw/jun10/ asw_jun10.pdf $>$. Acesso em: 15 set. 2011.

Brasil. Portaria no 1.627/SAR, de 16 ago. 2012. Aprova a Instrução Suplementar no 21-013 (Revisão A) da ANAC, que 
trata de instruções para obtenção de aprovação de instalação de equipamentos GNSS (Global Navigation Satellite Systems) stand alone para operações VFR e IFR PBN (PerformanceBased Navigation). Diário Oficial [da] República Federativa do Brasil. Poder Executivo, Brasília, DF, 17 ago. 2012, Seção 1, p. 2. Disponível em: < http://www2.anac.gov.br/biblioteca/IS/ IS\%2021-013A.pdf > . Acesso em: 04 mar. 2014.

Brasil. Portaria no 372/SSO, de 7 fev. 2013. Aprova a Instrução Suplementar no 91-001 (Revisão C) da ANAC, que trata da aprovação de aeronaves e operadores para condução de operações PBN. Diário Oficial [da] República Federativa do Brasil. Poder Executivo, Brasília, DF, 8 fev. 2013, Seção 1, p. 15. Disponível em: <http://www2.anac.gov.br/biblioteca/ IS/2013/IS91-001C.pdf>. Acesso em: 04 mar. 2014.

Brasil. Resolução no 305, de 18 fev. 2014. Aprova a Emenda no 02 do Regulamento Brasileiro de Aviação Civil - RBAC no 61, que trata das licenças, habilitações e certificados para pilotos. Diário Oficial [da] República Federativa do Brasil. Poder Executivo, Brasília, DF, 21 fev.

Federal Aviation Administration - FAA. General Aviation Technically Advanced Aircraft, FAA-Industry, Safety Study, Final report of TAA Safety study team, março 2003. Disponível em: <http://www.faa.gov/training testing/training/fits/research/ media/TAA\%20Final\%20Report.pdf $>$. Acesso em: 18 abr. 2011.

Henriqson E, Carim GCJ, Gamermann RW. Fatores humanos no design de cabines de comando. Revista Conexão SIPAER, 2011; 2(2):13-44. Disponível em: <http://www. google.com.br/url? sa $=$ t\&rct $=\mathrm{j} \& q=$ fatores $\% 20$ humanos $\% 20$ no $\% 20$ design $\% 20$ de $\% 20$ cabines $\% 20$ de $\% 20$ comando. $\% 20$ revista\%20conex\%C3\%A3o\%20sipaer\&source = web\&cd =3\&s $\mathrm{qi}=2$ \&ved $=0 \mathrm{CFUQFjAC \& url}=\mathrm{http} \% 3 \mathrm{~A} \% 2 \mathrm{~F} \% 2$ Finseer.ibict. br\%2Fsipaer\%2Findex.php\%2Fsipaer\%2Farticle\%2Fdownload\%2 F75\%2F109\&ei=W6bsT-r-KO2K6QGe7pG BQ\&usg=AFQjCN GImim0w3NhYJJwEHIV00rc-JUBeQ>. Acesso em: 20 out. 2011.
Hollnagel E, Woods DD. Joint Cognitive Systems: foundation of Cognitive Systems Engineering. Boca Raton, FL: Taylor \& Francis/CRC; 2005.

Kaber DB, Riley JM, Tan K. Improved usability of aviation automation through direct manipulation and graphical user interface design. Disponível em: <http://209.238.175.8/Papers/ pdf/Kaber etal IJAP 02.pdf>. Acesso em: 13 set. 2011.

International Civil Aviation Organization - ICAO. DOC 9683: Human Factors Training Manual - Training issues in automation and advanced technology flight decks. Montreal: Ed Intl Civil Aviation Organization; 1998. (Parte 2, cap 3, p. 297-337).

Monteiro RF. Novas tecnologias de cabine em aviões do transporte aéreo regular e transformações na representação social dos pilotos. Goiania. 2007. 160f. [Dissertação - Mestrado em Psicologia]. Universidade Católica de Goiás, Goiania, 2007.

National Transportation Safety Board - NTSB. Introduction of Glass Cockpit Avionics into Light Aircraft. Safety Study. Washington, DC, 2010. Disponível em: < http://www.safetybok. org/introduction_of_glass_cockpit_avionics_into_light_aircraft/ $>$. Acesso em: 20 abr. 2011.

Ribeiro EF. A formação do piloto de linha aérea: caso VARIG O ensino aeronáutico acompanhando a evolução tecnológica. Porto Alegre. 2008. 386f. [Tese - Doutorado em História]. Faculdade de Filosofia e Ciências Humanas, Pontifícia Universidade Católica do Rio Grande do Sul, Porto Alegre, 2008.

Sheridan TB, Parasuraman R. Reviews of human factors and ergonomics 2005; 1:189-192.

Correspondence address:

Rejane de Souza Fontes

Rua Noronha Torrezão, 212, apto. 602 - Santa Rosa

24240-182 Niterói, RJ, Brasil

Tel.: (21) 9919-9277

<rejane.fontes@anac.gov.br> 